\title{
Effects of coenzyme Q10 supplementation (300 mg/day) on antioxidation and anti-inflammation in coronary artery disease patients during statins therapy: a randomized, placebo-controlled trial
}

Bor-Jen Lee', Yu-Fen Tseng ${ }^{2}$, Chi-Hua Yen ${ }^{3,4,5}$ and Ping-Ting Lin ${ }^{2,6^{*}}$

\begin{abstract}
Background: High oxidative stress and chronic inflammation can contribute to the pathogenesis of coronary artery disease (CAD). Coenzyme Q10 is an endogenous lipid-soluble antioxidant. Statins therapy can reduce the biosynthesis of coenzyme Q10. The purpose of this study was to investigate the effects of a coenzyme Q10 supplement (300 mg/d; 150 mg/b.i.d) on antioxidation and anti-inflammation in patients who have CAD during statins therapy.

Methods: Patients who were identified by cardiac catheterization as having at least 50\% stenosis of one major coronary artery and who were treated with statins for at least one month were enrolled in this study. The subjects $(\mathrm{n}=51)$ were randomly assigned to the placebo $(\mathrm{n}=24)$ and coenzyme Q10 groups (Q10-300 group, $n=27)$. The intervention was administered for 12 weeks. The concentrations of coenzyme Q10, vitamin E, antioxidant enzymes activities (superoxide dismutase, catalase, and glutathione peroxidase), and inflammatory markers [C-reactive protein (CRP), tumor necrosis factor-a (TNF-a), and interleukin-6 (IL-6)] were measured in the 42 subjects (placebo, $n=19$; Q10-300, $n=23$ ) who completed the study.
\end{abstract}

Results: The levels of the plasma coenzyme Q10 $(P<0.001)$ and antioxidant enzymes activities $(P<0.05)$ were significantly higher after coenzyme Q10 supplementation. The levels of inflammatory markers (TNF-a, $P=0.039)$ were significantly lower after coenzyme Q10 supplementation. The subjects in the Q10-300 group had significantly higher vitamin $E(P=0.043)$ and the antioxidant enzymes activities $(P<0.05)$ than the placebo group at week 12 . The level of plasma coenzyme Q10 was significantly positively correlated with vitamin $\mathrm{E}(P=0.008)$ and antioxidant enzymes activities $(P<0.05)$ and was negatively correlated with TNF-a $(P=0.034)$ and IL-6 $(P=0.027)$ after coenzyme Q10 supplementation.

Conclusion: Coenzyme Q10 supplementation at 300 mg/d significantly enhances antioxidant enzymes activities and lowers inflammation in patients who have CAD during statins therapy.

Trial registration: Clinical Trials.gov Identifier: NCT01424761.

Keywords: Coenzyme Q10, Statins, Antioxidation, Inflammation, Coronary artery disease

\footnotetext{
* Correspondence: apt810@csmu.edu.tw

${ }^{2}$ School of Nutrition, Chung Shan Medical University, Taichung 40201, Taiwan

${ }^{6}$ Department of Nutrition, Chung Shan Medical University Hospital, Taichung 40201, Taiwan

Full list of author information is available at the end of the article
} 


\section{Background}

Cardiovascular disease is the leading cause of death worldwide [1]. Hyperlipidemia is a major risk factor for coronary artery disease (CAD). A higher level of low density lipoprotein-cholesterol (LDL-C) can increase the incidence of CAD [2]. The 3-hydroxy-3-methylglutaryl coenzyme A reductase (HMG-Co A reductase) inhibitors (statins) have been the most popular drugs for reducing the level of LDL-C, and they are an established strategy for decreasing the frequency of CAD events [3]. Coenzyme Q10 (also called ubiquinone) is a lipid-soluble benzoquinone that has 10 isoprenyl units in its side chain and is a key component of the mitochondrial respiratory chain for adenosine triphosphate synthesis $[4,5]$. Statins can decrease the synthesis of cholesterol and other molecules downstream of mevalonate. Mevalonate is a precursor of coenzyme Q10. Statins not only lower the blood cholesterol but also lower the level of coenzyme Q10 [6-9].

Higher levels of oxidative stress and inflammation play a role in the development of CAD $[10,11]$. Coenzyme Q10 is an intracellular antioxidant that protects the membrane phospholipids, mitochondrial membrane protein, and LDL$\mathrm{C}$ from free radical-induced oxidative damage [12,13]. Recently, we have demonstrated that coenzyme Q10 had a cardio-protective impact on CAD. A higher level of plasma coenzyme Q10 ( $\geq 0.52 \mu \mathrm{mol} / \mathrm{L})$ was significantly associated with a reduced the risk of CAD [14]. We proposed that a higher dose of coenzyme Q10 (> $150 \mathrm{mg} / \mathrm{d}$ ) might show better antioxidation in patients who have CAD [15].

The circulating levels of C-reactive protein (CRP), tumor necrosis factor- $\alpha$ (TNF- $\alpha$ ), and interleukin-6 (IL-6) are positively correlated with the risk of primary and recurrent myocardial infarction and death [16-18]. Adiponectin is an anti-inflammatory marker that is potentially antiatherogenic and is secreted in abundance by adipocytes [19]. Its level might be related to the development of CAD [20]. In a recent study [21], we reported that coenzyme Q10 administered at $150 \mathrm{mg} / \mathrm{d}$ decreased the inflammatory marker IL-6 but had no effect on CRP in patients with CAD. Thus, we hypothesize that a higher dose of coenzyme Q10 (> $150 \mathrm{mg} / \mathrm{d}$ ) would provide better anti-inflammation in CAD patients. The purpose of this study was to investigate the effect of coenzyme Q10 supplementation (300 mg/day, $150 \mathrm{mg} / \mathrm{b} . \mathrm{i} . \mathrm{d})$ on antioxidant enzymes activities and antiinflammation in patients with CAD during statins therapy.

\section{Methods}

\section{Participants}

This study was designed as a single blinded, randomized, parallel, placebo-controlled study. CAD patients were recruited from the cardiology clinic of Taichung Veterans General Hospital, which is a teaching hospital in central Taiwan. CAD was identified by cardiac catheterization as having at least $50 \%$ stenosis of one major coronary artery or receiving percutaneous transluminal coronary angioplasty (PTCA). The subjects in this study were treated with statins therapy for at least 1 month. The subjects with diabetes, liver, or renal diseases, or who currently use vitamin supplements were excluded. Informed consent was obtained from each subject. This study was approved by the Institutional Review Board of Taichung Veterans General Hospital, Taiwan.

With a sample size calculation, we expected that the change in the levels of antioxidant enzymes activities would be $5.0 \pm 7.0 \mathrm{U} / \mathrm{mg}$ of protein after coenzyme Q10 supplementation; therefore, the desired power was set at 0.8 to detect a true fact and at an $\alpha$ value equal to 0.05 with a minimal sample of 18 in each intervention group. We enrolled 51 CAD patients in this study and used random numbers table to random assign the subjects to the placebo $(\mathrm{n}=24)$ or to the coenzyme Q10 [300 mg/day (Q10-300 group), $\mathrm{n}=27$ ] groups. The female subjects in this study were postmenopausal women who were not receiving hormone therapy. The coenzyme Q10 and placebo (starch) capsules were commercially available preparations (New Health Taiwan Co., Ltd.). The intervention was administered for 12 weeks. The subjects were instructed to take two capsules daily (coenzyme Q10 supplements $300 \mathrm{mg} / \mathrm{d}, 150 \mathrm{mg} / \mathrm{b} . \mathrm{i} . \mathrm{d})$. To monitor compliance, the researchers reminded subjects to check the capsules bag every 4 weeks to confirm that the bag was empty. The researcher also asked some questions to the subjects, such as (1)When did you take the supplements? (We advised subjects to take the supplements after a meal); (2) How many times did you take the supplements every day? (We advised subjects to take the supplements two times per day); (3How many capsules did you take of the supplements each time? (We advised the subjects to take one capsule of supplement each time); and (4)How did you feel after taking the supplements? (for monitoring adverse effects), and then we checked the capsule bags. We placed 56 capsules in each bag, and the bag should be emptied after 4 weeks of taking the supplements. If the subjects took the empty bag back and answered the questions correctly, the researcher then gave them another bag of capsules. In addition, we also measured the concentration of coenzyme Q10 every 4 weeks supplementation for monitor the compliance of the subjects. The age, blood pressures, and smoking, drinking, and exercise habits of all of the subjects were recorded. The body weight and height were measured; the body mass index (BMI) was then calculated.

\section{Blood collection and biochemical measurements}

Fasting venous blood samples $(15 \mathrm{~mL})$ were obtained to estimate the hematological and vitamin status. Blood specimens were collected in Vacutainer tubes (Becton Dickinson, Rutherford, NJ, USA) that contained EDTA as an anticoagulant or that contained no anticoagulant 
as required. Serum and plasma were prepared after centrifugation $\left(3,000 \mathrm{rpm}, 4^{\circ} \mathrm{C}, 15\right.$ minutes) and were then stored at $-80^{\circ} \mathrm{C}$ until analysis. Hematological entities [serum creatinine, total cholesterol (TC), triglyceride, LDL-C, and high density lipoprotein-cholesterol (HDL-C)] were measured by an automated biochemical analyzer (Hitachi-7180E, Tokyo, Japan). The level of CRP was quantified by particleenhanced immunonephelometry with an Image analyzer (Dade Behring, IL, USA). Plasma TNF- $\alpha$ (R\&D Systems Inc., Minneapolis, USA), IL-6 (eBioscience, CA, USA), and adiponectin (BioVendor, Brno, Czech Republic) levels were measured by enzyme-linked immunosorbent assay (ELISA) using commercially available kits and according to the instructions made available from the suppliers.

Plasma coenzyme Q10 and vitamin E were measured by high-performance liquid chromatography (HPLC) and were detected by a UV detector at $275 \mathrm{~nm}$ and $292 \mathrm{~nm}$, respectively [22,23]. The red blood cell (RBC) samples were washed with normal saline after removing the plasma. Then, the RBC were diluted with $25 \mathrm{x}$ sodium phosphate buffer for superoxide dismutase (SOD) and glutathione peroxidase (GPx) measurements, and with 250x sodium phosphate buffer for catalase (CAT) measurement. The antioxidant enzymes activities (CAT, SOD, and GPx) were determined in the fresh samples and the methods for measuring these activities have been described previously [24-26]. The protein content of the plasma and RBC was determined based on the biuret reaction of the BCA kit (Thermo, Rockford, IL, USA). The values of the antioxidant enzymes activities were expressed as unit/mg of protein. All of the analyses were performed in duplicate.

\section{Statistical analyses}

The data were analyzed using SigmaPlot software (version 12.0, Systat, San Jose, CA, USA). The normality of the distribution of the variables was evaluated using the Shapiro-Wilk test, and the normally distributed variables were age, waist circumference, the ratio of waist to hip, BMI, TC, LDL-C, HDL-C, the frequency of smoking and exercise, the ratio of vitamin $\mathrm{E}$ to $\mathrm{TC}$, SOD, and IL-6. The multiple linear regression analyses were performed to examine the time and the interventional effects on the variables (coenzyme Q10, vitamin E, antioxidant enzymes, and inflammation markers as a dependent variable). We set the dummy variables for the time $(0=$ baseline, $1=$ week 12$)$ and the intervention $(0=$ placebo, 1 = coenzyme Q10 supplementation). If the variables had significantly effects by the time or the intervention, then the intergroup differences (intervention effect) between the placebo and the Q10-300 groups were evaluated by the Student's t-test or the Mann-Whitney rank sum test; within a group (time effect), the paired t-test or the Wilcoxon signed rank tests were used. When comparing the changed levels of coenzyme Q10, vitamin E, antioxidant enzymes activities and inflammatory markers between the placebo and the Q10300 groups, the Student's t-test or the Mann-Whitney rank sum test was used. For categorical response variables, the differences between two groups were assessed by the Chi-square test (parametric method) or the Fisher's exact test (non-parametric method). To examine the relationships of coenzyme Q10 concentration with the level of vitamin $\mathrm{E}$, antioxidant enzymes activities, and inflammatory markers after the supplementation, the Pearson product moment correlations were used in the parametric data and the Spearman rank order correlations were used in the non-parametric data. The results were considered to be statistically significant at $p<0.05$. The values presented in the text are means \pm standard deviation (SD).

\section{Results}

\section{Study participant characteristics}

The sampling and trial profiles are summarized in Figure 1, along with the number of subjects who completed the study in each group. Table 1 shows the demographic data and the health characteristics of the subjects. There were no significant differences between the two groups with respect to age, BMI, blood pressure, anthropometric measurements, hematological entities (serum creatinine and lipid profiles), and the frequency of smoking, drinking, or exercise at baseline.

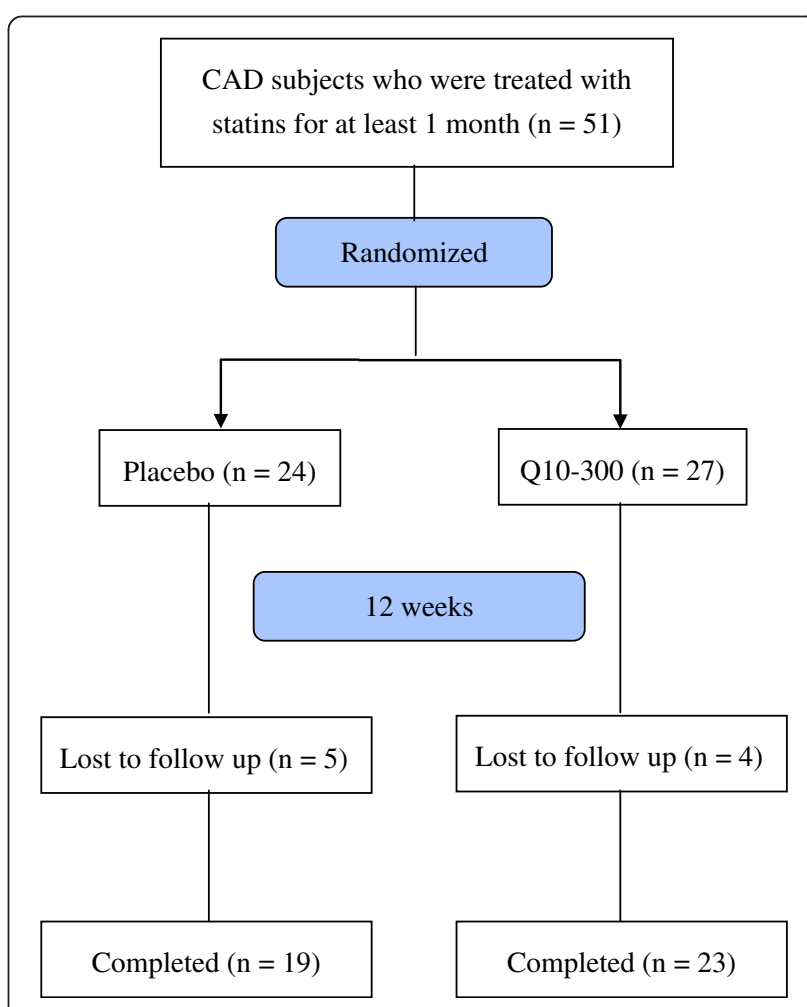

Figure 1 Flow diagram. Q10-300, coenzyme Q10 300 mg/d. 
Table 1 Characteristics of subjects

\begin{tabular}{|c|c|c|c|}
\hline & Placebo $(n=19)$ & Q10-300 $(n=23)$ & $P$ values ${ }^{1}$ \\
\hline Male / female (n) & $12 / 7$ & $19 / 4$ & $0.180^{\mathrm{a}}$ \\
\hline Age $(y)$ & $66.5 \pm 11.1(68.0)$ & $71.7 \pm 11.5(72.0)$ & $0.148^{b}$ \\
\hline SBP $(\mathrm{mmHg})$ & $133.6 \pm 6.9(130.0)$ & $131.8 \pm 12.0(130.0)$ & $0.175^{c}$ \\
\hline $\mathrm{DBP}(\mathrm{mmHg})$ & $75.5 \pm 5.2(74.0)$ & $73.8 \pm 7.1(70.0)$ & $0.234^{c}$ \\
\hline Waist circumference $(\mathrm{cm})$ & $95.2 \pm 10.0(96.0)$ & $92.1 \pm 11.3(90.0)$ & $0.362^{b}$ \\
\hline Waist hip ratio & $1.0 \pm 0.1(0.9)$ & $0.9 \pm 0.1(0.9)$ & $0.743^{b}$ \\
\hline BMI $\left(\mathrm{kg} / \mathrm{m}^{2}\right)$ & $26.7 \pm 3.2(26.5)$ & $25.9 \pm 3.5(25.3)$ & $0.438^{b}$ \\
\hline Current smoker ${ }^{2}, \mathrm{n}(\%)$ & $4(21.1 \%)$ & $1(4.3 \%)$ & $0.158^{d}$ \\
\hline Drink alcohol ${ }^{3}, \mathrm{n}(\%)$ & $2(10.5 \%)$ & $3(13.0 \%)$ & $1.000^{\mathrm{a}}$ \\
\hline Exercise $^{4}, \mathrm{n}(\%)$ & $13(68.4 \%)$ & $15(65.2 \%)$ & $0.913^{d}$ \\
\hline Creatinine $(\mu \mathrm{mol} / \mathrm{L})$ & $123.8 \pm 70.7(106.1)$ & $114.9 \pm 44.2(97.2)$ & $0.780^{c}$ \\
\hline $\mathrm{TC}(\mathrm{mmol} / \mathrm{L})$ & $4.5 \pm 1.3(4.4)$ & $5.0 \pm 1.0(4.9)$ & $0.175^{b}$ \\
\hline TG $(\mathrm{mmol} / \mathrm{L})$ & $1.7 \pm 1.3(1.3)$ & $1.6 \pm 0.9(1.4)$ & $0.791^{c}$ \\
\hline LDL-C (mmol/L) & $2.7 \pm 0.8(2.5)$ & $3.0 \pm 0.8(3.1)$ & $0.165^{b}$ \\
\hline $\mathrm{HDL}-\mathrm{C}(\mathrm{mmol} / \mathrm{L})$ & $1.4 \pm 0.4(1.4)$ & $1.4 \pm 0.3(1.4)$ & $0.984^{b}$ \\
\hline
\end{tabular}

Data are mean \pm SD (median).

1 values are significantly different between the placebo and Q10-300 groups.

${ }^{2}$ current smoker: individual currently smoking one or more cigarettes per day.

${ }^{3}$ drink alcohol: individual drinking one or more drink per day regularly.

${ }^{4}$ exercise: individual exercise at least 3 times every week.

${ }^{a}$ data were analyzed by the Fisher's exact test.

bdata were analyzed by the Student's t-test.

'data were analyzed by the Mann-Whitney rank sum test.

${ }^{d}$ data were analyzed by the Chi-square test.

$B M I$, body mass index; $D B P$, diastolic blood pressure; $H D L-C$, high-density lipoprotein-cholesterol; $L D L-C$, low density lipoprotein-cholesterol; SBP, systolic blood pressure; $T C$, total cholesterol; $T G$, triglyceride.

\section{Plasma coenzyme Q10 and vitamin E concentrations}

The effects of coenzyme Q10 supplementation on the levels of coenzyme Q10 and vitamin E are shown in Figure 2. The plasma coenzyme Q10 concentration $(P<0.001)$ and the ratio of coenzyme Q10 to TC $(P<0.001)$ were significantly increased after coenzyme Q10 supplementation. The subjects in the Q10-300 group had significantly higher levels of coenzyme Q10 $(P<0.001)$, ratio of coenzyme Q10 to TC $(P<0.001)$, and vitamin $\mathrm{E}(P=0.043)$, and ratio of vitamin $\mathrm{E}$ to TC $(P=0.025)$ than those in the placebo group at week 12 .

\section{Antioxidant enzymes activities}

The effects of coenzyme Q10 supplementation on the antioxidant enzymes activities are shown in Figure 3. The activities of SOD $(P=0.001)$, CAT $(P=0.009)$, and GPx $(P=0.021)$ were significantly increased after coenzyme Q10 supplementation. The subjects in the Q10300 group had significantly higher activities of SOD $(P=$ $0.005)$, CAT $(P=0.025)$, and GPx $(P=0.040)$ than those in the placebo group at week 12 .

\section{Inflammatory markers}

The effects of coenzyme Q10 supplementation on the levels of inflammatory markers are shown in Figure 4. The subjects in the Q10-300 group had a significantly lower level of TNF- $\alpha$ than those in the placebo group at week 12 $(P=0.039)$. There were no effects on the level of CRP, IL6 , and adiponectin after 12 weeks of supplementation.

\section{Changed levels of coenzyme Q10, vitamin E, antioxidant} enzymes activities, and inflammatory markers after supplementation

The changed levels of coenzyme Q10, vitamin E, antioxidant enzymes activities, and inflammatory markers after the supplementation are shown in Table 2. The Changed levels of coenzyme Q10 $(P<0.001)$, the ratios of coenzyme Q10 to TC $(P<0.001)$, vitamin E $(P=0.046)$, the ratios of vitamin $\mathrm{E}$ to TC $(P=0.032)$, antioxidant enzymes activities (SOD, $P=0.034$; CAT, $P=0.033$; GPx, $P=0.042$ ), and inflammatory markers (TNF- $\alpha, P=0.036$; IL-6, $P=0.040$ ) were significantly different between the placebo and the Q10-300 groups.

\section{Correlations between coenzyme Q10, vitamin E,} antioxidant enzymes activities, and inflammatory markers The correlations between coenzyme Q10, vitamin E, antioxidant enzymes activities, and inflammatory markers after coenzyme Q10 supplementation are shown in Table 3. The plasma coenzyme Q10 concentration was significantly 

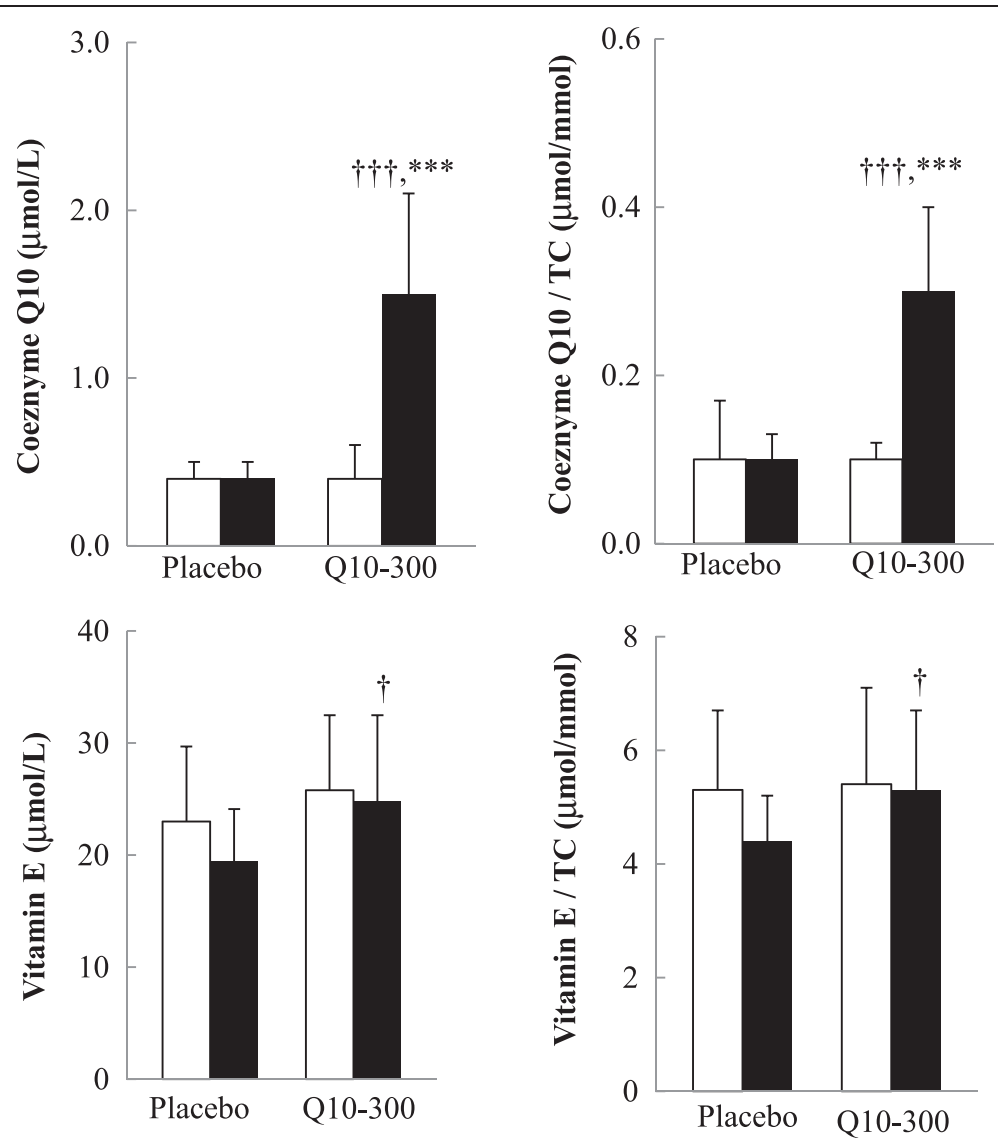

Figure 2 Coenzyme Q10 and vitamin E concentrations. Data are means \pm SD. $\square$ week 0 , - week 12. *Values were significantly different after intervention within the group $\left({ }^{* * *} P<0.001\right)$. +Values were significantly different between the placebo and Q10-300 groups $\left({ }^{\dagger} P<0.05,{ }^{++\dagger} P<0.001\right)$. TC, total cholesterol.

correlated with the vitamin $\mathrm{E}(r=0.41, P=0.008)$, antioxidant enzymes activities (SOD, $r=0.38, P=0.011$; CAT, $r=$ $0.30, P=0.0038$; GPx, $r=0.32, P=0.043)$, and the inflammatory markers (TNF- $\alpha, r=-0.33, P=0.034$; IL-6, $r=-0.38$, $P=0.027)$ at week 12 .

\section{Discussion}

In this clinical trial, we have demonstrated that coenzyme Q10 at the dose of $300 \mathrm{mg} / \mathrm{d}$ for 12 weeks increases the antioxidant enzymes activities (SOD, CAT, and GPx) and decreases inflammation in patients with
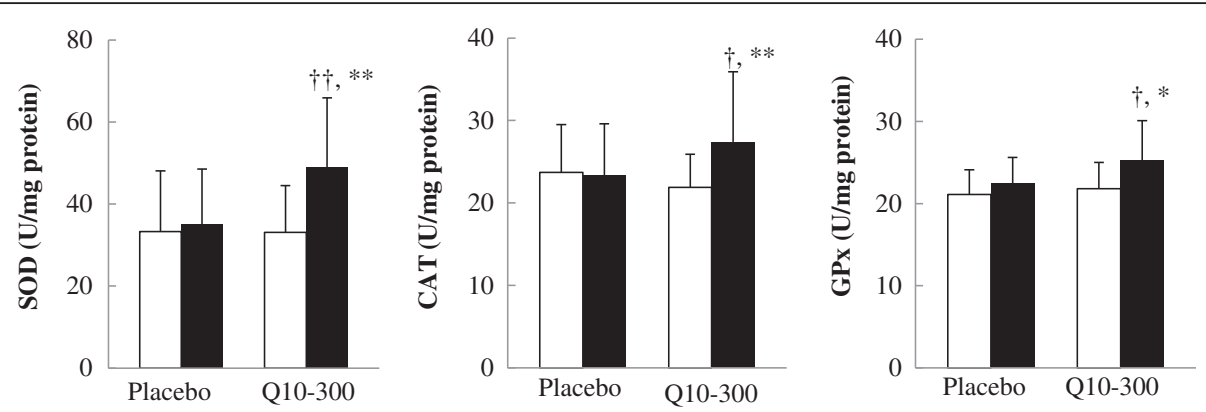

Figure 3 Antioxidant enzymes activities. Data are means \pm SD. $\square$ week 0 , a week 12. *Values were significantly different after intervention within the group $\left({ }^{*} P<0.05,{ }^{* *} P<0.01\right)$. +Values were significantly different between the placebo and Q10-300 groups $\left({ }^{\dagger} P<0.05\right.$, $\left.{ }^{\dagger \dagger} P<0.01\right)$. CAT, catalase; GPx, glutathione peroxidase; SOD, superoxide dismutase. 

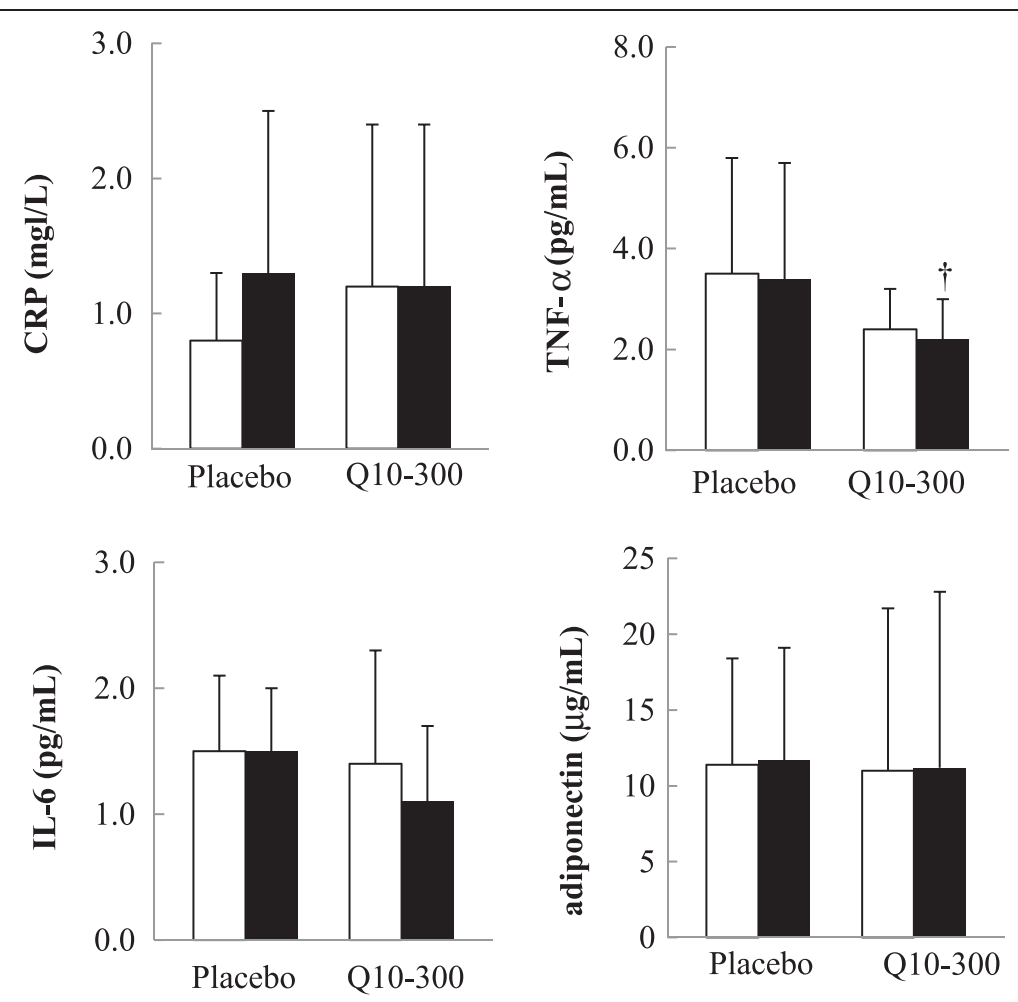

Figure 4 The level of inflammatory markers. Data are means \pm SD. $\square$ week 0 , $\mathbf{n}$ week 12 . †Values were significantly different between the placebo and Q10-300 groups ( $\left.{ }^{\dagger} P<0.05\right)$. CRP, C-reactive protein; IL-6, interleukin-6; TNF-a, tumor necrosis factor-a.

CAD during statins therapy. Tiano et al. [27] administered coenzyme Q10 (300 $\mathrm{mg} / \mathrm{d})$ to patients with ischemic heart disease for 1 month, and they observed that those patients' extracellular superoxide dismutase activity and endothelium-dependent vasodilatation were improved after supplementation. Antioxidant enzymes such as SOD, CAT, and GPx are the first line of defense against reactive oxygen species [28], and a decrease in their activities contributes to the elevated oxidative stress in CAD patients [14]. Our previous results showed that coenzyme Q10 at a

Table 2 Changed levels of coenzyme Q10, vitamin E, antioxidant enzymes activities, and inflammatory markers after supplementation

\begin{tabular}{|c|c|c|c|}
\hline & Placebo $(n=19)$ & Q10-300 ( $n=23)$ & $P$ values ${ }^{1}$ \\
\hline Coenzyme Q10 ( $\mathrm{mmol} / \mathrm{L})$ & $-0.01 \pm 0.09(-0.03)$ & $1.10 \pm 0.54(1.26)$ & $<0.001^{b}$ \\
\hline Coenzyme Q10/TC ( $\mu \mathrm{mol} / \mathrm{mmol})$ & $-0.01 \pm 0.07(-0.00)$ & $0.25 \pm 0.11(0.25)$ & $<0.001^{b}$ \\
\hline Vitamin E ( $\mu \mathrm{mol} / \mathrm{L})$ & $-3.35 \pm 4.51(-3.08)$ & $-0.29 \pm 4.03(-0.83)$ & $0.046^{b}$ \\
\hline Vitamin E/TC ( $\mu \mathrm{mol} / \mathrm{mmol})$ & $-0.88 \pm 1.45(-0.55)$ & $0.07 \pm 1.08(0.11)$ & $0.032^{a}$ \\
\hline SOD (U/mg protein) & $1.63 \pm 21.54(3.63)$ & $15.90 \pm 20.48(12.91)$ & $0.034^{a}$ \\
\hline CAT (U/mg protein) & $-1.42 \pm 8.26(-1.18)$ & $6.17 \pm 11.28(3.18)$ & $0.033^{b}$ \\
\hline GPx (U/mg protein) & $0.91 \pm 3.70(-0.24)$ & $4.62 \pm 6.52(2.15)$ & $0.042^{b}$ \\
\hline CRP (mg/L) & $0.39 \pm 1.24(0.00)$ & $-0.20 \pm 0.73(0.00)$ & $0.343^{b}$ \\
\hline TNF-a (pg/mL) & $0.17 \pm 0.77(0.08)$ & $-0.30 \pm 0.35(-0.26)$ & $0.036^{b}$ \\
\hline IL-6 (pg/mL) & $0.08 \pm 0.64(-0.11)$ & $-0.52 \pm 0.79(-0.14)$ & $0.040^{a}$ \\
\hline Adiponectin $(\mu \mathrm{g} / \mathrm{mL})$ & $0.36 \pm 2.89(0.30)$ & $0.19 \pm 1.88(-0.20)$ & $0.71^{b}$ \\
\hline
\end{tabular}

Data are mean \pm SD (median).

${ }^{1}$ values are significantly different between the placebo and the Q10-300 groups.

adata were analyzed by the Student's t-test.

${ }^{b}$ data were analyzed by the Mann-Whitney rank sum test.

$C A T$, catalase; $C R P, C$-reactive protein; GPX, glutathione peroxidase; IL-6, interleukin-6; SOD, superoxide dismutase; $T C$, total cholesterol; $T N F-a$, tumor necrosis factor-a. 
Table 3 Correlations between coenzyme Q10, vitamin E, antioxidant enzymes activities, and inflammatory markers after coenzyme Q10 supplementation

\begin{tabular}{|c|c|}
\hline & Coenzyme Q10 ( $\mu \mathrm{mol} / \mathrm{L}) r^{1}(P$ values $)$ \\
\hline Vitamin E ( $\mu \mathrm{mol} / \mathrm{L})$ & $0.41(0.008)^{a}$ \\
\hline SOD (unit/mg protein) & $0.38(0.011)^{\mathrm{a}}$ \\
\hline CAT (unit/mg protein) & $0.30(0.038)^{b}$ \\
\hline GPx (unit/mg protein) & $0.32(0.043)^{b}$ \\
\hline CRP (mg/L) & $-0.08(0.621)^{b}$ \\
\hline TNF-a (pg/mL) & $-0.33(0.034)^{b}$ \\
\hline IL-6 (pg/mL) & $-0.38(0.027)^{\mathrm{a}}$ \\
\hline Adiponectin $(\mu \mathrm{g} / \mathrm{mL})$ & $-0.21(0.190)^{b}$ \\
\hline
\end{tabular}

${ }^{1}$ correlation coefficient.

${ }^{a}$ data were analyzed by the Pearson product moment correlation.

bdata were analyzed by the Spearman rank order correlation.

CAT, catalase; CRP, C-reactive protein; GPx, glutathione peroxidase; IL-6, interleukin-6; SOD, superoxide dismutase; TNF- $\alpha$, tumor necrosis factor- $\alpha$.

dose of $150 \mathrm{mg} / \mathrm{d}$ increased the activity of SOD by $22.2 \%$ and of CAT by $4.5 \%$, but had no effect on that of GPx [15]. In the present study, coenzyme Q10 supplementation at $300 \mathrm{mg} / \mathrm{d}$ increased the activity of SOD by $48.5 \%$, CAT by $9.1 \%$, and GPx by $4.3 \%$, and the antioxidant enzymes activities were all positively correlated with the level of coenzyme Q10 after 12 weeks of supplementation (Table 3). It appears that the $300 \mathrm{mg}$ dose of coenzyme Q10 has better antioxidation than $150 \mathrm{mg} / \mathrm{d}$.

Both groups of statins-treated CAD patients in this study had a low level of coenzyme Q10 at baseline (Figure 2), and the level of coenzyme Q10 was significantly increased by approximately 5 -fold after 4 weeks of coenzyme Q10 supplementation (data not shown; the median level of coenzyme Q10 was 0.4 to $2.0 \mu \mathrm{mol} / \mathrm{L}$ ), which rapidly adjusted their low coenzyme Q10 level to normal values $(0.5-$ $1.7 \mu \mathrm{mol} / \mathrm{L})$ [29]. In addition, coenzyme Q10 had a synergic effect with vitamin E [30-33]. In this study, we observed that the level of vitamin $E$ was significantly higher in the Q10-300 group (Figure 2) and was positively correlated with the level of coenzyme Q10 after 12 weeks of supplementation (Table 3 ). Coenzyme Q10 not only protects vitamin $\mathrm{E}$ against superoxide-driven oxidation but also regenerates vitamin $\mathrm{E}$ during antioxidation processes [32,33].

CAD is considered to be a chronic inflammation status [10]. In the present study, the level of TNF- $\alpha$ (Figure 4) and the changed levels of TNF- $\alpha$ and IL- 6 were significantly decreased after coenzyme Q10 supplementation (Table 2). The level of coenzyme Q10 was significantly negatively correlated with inflammatory markers (TNF- $\alpha$ and IL-6) (Table 3). Schmelzer et al. [34,35] demonstrated that coenzyme Q10 could exert anti-inflammation effects via the reduction of nuclear factor- $\mathrm{kB}(\mathrm{NF}-\mathrm{kB})$ dependent gene expression. NF-kB can be activated by the reactive oxygen species and can then up-regulate pro-inflammatory cytokines expression. However, this NF- $\mathrm{kB}$-activating cascade could be inhibited by antioxidants, such as coenzyme Q10 [36]. Our previous results [21] showed that coenzyme Q10 at a dose of $150 \mathrm{mg} / \mathrm{d}$ decreased the level of IL-6 by $0.40 \mathrm{pg} / \mathrm{mL}$. In the present study, coenzyme Q10 supplementation at $300 \mathrm{mg} / \mathrm{d}$ decreased the levels of TNF- $\alpha$ by $0.30 \mathrm{pg} / \mathrm{mL}$ and IL- 6 by $0.52 \mathrm{pg} / \mathrm{mL}$. However, coenzyme Q10 supplementation had no effect on the level of CRP. As we previously reported, proinflammatory cytokines (TNF- $\alpha$ and IL-6) reflect the status of inflammatory reactions with more sensitivity (easily changed) than CRP, which is a product of hepatic stimulation [21]. A higher level of adiponectin is associated with a lower risk of CAD [20,37], but coenzyme Q10 supplementation had no effect on the level of adiponectin in the present study. Nakamura et al. [20] reported that the concentration of plasma adiponectin was not significantly different between stable angina pectoris and control subjects. The subjects who had CAD in this study had not experienced acute myocardial infarction within the previous 6 months and thus were stable angina pectoris patients, which might be the reason why we did not find an effect of coenzyme Q10 on adiponectin.

Regarding the safety of statins therapy and its combination with placebo or coenzyme Q10 in the present study, there were no clinically significant changes in the subjects' vital signs, serum chemical values, or hematological values, and there were no serious adverse events, no complaints of myalgia or muscle weakness, and no withdrawals due to adverse events. Thus, coenzyme Q10 at a dose of $300 \mathrm{mg} / \mathrm{d}$ is safe for co-administration with statins therapy.

Two limitations of the present study should be mentioned. First, the number of participants was small, although we did recruit more subjects than expected. Second, a few of the subjects had higher inflammation in the present study. Only $10 \%$ of the subjects had a high inflammation according to the level of CRP $(\geq 3.0 \mathrm{mg} / \mathrm{L})$, and this finding might have contributed to observing the null effect on CRP after the supplementation. Large studies are needed to establish the beneficial effect of coenzyme Q10 supplementation on inflammation, especially in subjects who have high inflammation status.

\section{Conclusions}

In conclusion, we have demonstrated that coenzyme Q10 supplementation at a dose of $300 \mathrm{mg} / \mathrm{d}$ significantly increased antioxidant enzymes activities and reduced the levels of inflammatory markers (TNF- $\alpha$ and IL-6) in CAD patients during statins therapy. CAD patients might benefit from using coenzyme Q10 supplements to increase their antioxidation and anti-inflammation capacity during statins therapy. 


\section{Competing interests}

The authors have no conflict of interest.

\section{Authors' contributions}

BJL carried out the study, performed the data analyses, and drafted the manuscript. YFT and CHY carried out the study and sample analyses. PTL conceived of the study, participated in its design, and coordination, and helped to draft the manuscript. All authors read and approved the final manuscript.

\section{Acknowledgments}

This study was supported by a grant from the National Science Council (NSC 100-2320-B-040-003), Taiwan. We would like to express our sincere appreciation to the subjects for their participation and to Dr. Hsia, who kindly provided the coenzyme Q10 supplements for this trial. We thank the nurses at Taichung Veterans General Hospital and the technical advisor of Taipei Institute of Pathology for providing expert assistance in blood sample collection and data analysis.

\section{Author details}

${ }^{1}$ The Intensive Care Unit, Taichung Veterans General Hospital, Taichung 40705, Taiwan. ${ }^{2}$ School of Nutrition, Chung Shan Medical University, Taichung 40201, Taiwan. ${ }^{3}$ Department of Family and Community Medicine, Chung Shan Medical University Hospital, Taichung 40201, Taiwan. ${ }^{4}$ School of Medicine, Chung Shan Medical University, Taichung 40201, Taiwan. ${ }^{5}$ Center for Education and Research on Geriatrics and Gerontology, Chung Shan Medical University, Taichung 40201, Taiwan. ${ }^{6}$ Department of Nutrition, Chung Shan Medical University Hospital, Taichung 40201, Taiwan.

Received: 12 August 2013 Accepted: 31 October 2013 Published: 6 November 2013

\section{References}

1. Braunwald E: Shattuck lecture-cardiovascular medicine at the turn of the millennium: triumphs, concerns, and opportunities. N Engl J Med 1997, 337:1360-1369.

2. Stamler J, Wentworth D, Neaton JD: Is relationship between serum cholesterol and risk of premature death from coronary heart disease continuous and graded? findings in 356,222 primary screenees of the multiple risk factor intervention trial (MRFIT). JAMA 1986, 256:2823-2828.

3. LaRosa JC, Grundy SM, Waters DD, Shear C, Barter P, Fruchart JC, Gotto AM, Greten H, Kastelein JJ, Shepherd J, Wenger NK, Treating to New Targets (TNT) Investigators: Intensive lipid lowering with atorvastatin in patients with stable coronary disease. N Engl J Med 2005, 352:1425-1435.

4. Ernster L, Dallner G: Biochemical, physiological and medical aspects of ubiquinone function. Biochim Giophys Acta 1995, 1271:195-204.

5. Bhagavan HN, Chopra RK: Coenzyme Q10: absorption, tissue uptake, metabolism and pharmacokinetics. Free Radic Res 2006, 40:445-453.

6. Folkers $\mathrm{K}$, Langsjoen $\mathrm{P}$, Willis $\mathrm{R}$, Richardson $\mathrm{P}, \mathrm{Xia} \mathrm{L}$,, $\mathrm{Ye} C \mathrm{CQ}$, Tamagawa $\mathrm{H}$ : Lovastatin decreases coenzyme Q10 levels in human. Proc Natl Acad Sci U S A 1990, 87:8931-8934.

7. Ghirlanda G, Oradei A, Manto A, Lippa S, Uccioli L, Caputo S, Greco AV, Littarru GR: Evidence of plasma CoQ10-lowering effect by HMG-CoA reductase inhibitors: a double-blind, placebo-controlled study. J Clin Pharmacol 1993, 33:26-29.

8. Mabuchi H, Higashikata T, Kawashiri M, Katsuda S, Mizuno M, Nohara A, Inazu A, Koizumi A, Kobayashi A: Reduction of serum ubiquinol-10 and ubiquinone-10 levels by atorvastatin in hypercholesterolemic patients. J Atheroscler Thromb 2005, 12:111-119.

9. Chu CS, Kou HS, Lee CJ, Lee KT, Chen SH, Voon WC, Sheu SH, Lai WT: Effect of atorvastatin withdrawal on circulating coenzyme Q10 concentration in patients with hypercholesterolemia. Biofactors 2006, 28:177-184.

10. Harrison D, Griendling KG, Landmesser U, Hornig B, Drexlar H: Role of oxidative stress in atherosclerosis. Am J Cardiol 2003, 91:7-11.

11. Siegel D, Devaraj S, Mitra A, Raychaudhuri SP, Raychaudhuri SK, Jialal I: Inflammation, atherosclerosis, and psoriasis. Clin Rev Allergy Immunol 2013, 44:194-204.

12. Alleva R, Tomasetti M, Battino M, Curatola G, Littarru GP, Folkers K: The roles of coenzyme Q10 and vitamin $\mathrm{E}$ on the peroxidation of human low density lipoprotein subfractions. Proc Natl Acad Sci U S A 1995, 26:9388-9391.
13. Singh U, Devaraj S, Jialal I: Coenzyme Q10 supplementation and heart failure. Nutr Rev 2007, 1:286-293.

14. Lee BJ, Lin YC, Huang YC, Ko YW, Hsia S, Lin PT: The relationship between coenzyme Q10 and oxidative stress, antioxidant enzymes activities and coronary artery disease. ScientificWorldJournal 2012, 2012:792756.

15. Lee BJ, Huang YC, Chen SJ, Lin PT: Coenzyme Q10 supplements reduce oxidative stress and increase activities of antioxidant enzymes in patients with coronary artery disease. Nutrition 2012, 28:250-255

16. Ma J, Hennekens $\mathrm{CH}$, Ridker PM, Stampfer MJ: A prospective study of fibrinogen and risk of myocardial infarction in the Physicians' health study. J Am Coll Cardiol 1999, 33:1347-1352.

17. Ridker PM, Rifai N, Pfeifer M, Sacks F, Lepage S, Braunwald E: Elevation of tumor necrosis factor-alpha and increased risk of recurrent coronary events after myocardial infarction. Circulation 2000, 101:2149-2153.

18. Ridker PM, Rifai N, Stampfer MJ, Hennekens CH: Plasma concentration of interleukin- 6 and the risk of future myocardial infarction among apparently healthy men. Circulation 2000, 101:1767-1772.

19. Dandona P, Aljada A, Chaudhuri A, Mohanty P, Garg R: Metabolic syndrome: a comprehensive perspective based on interactions between obesity, diabetes, and inflammation. Circulation 2005, 111:1448-1454

20. Nakamura $Y$, Shimada K, Fukuda D, Shimada $Y$, Ehara S, Hirose M, Kataoka T, Kamimori K, Shimodozono S, Kobayashi Y, Yoshiyama M, Takeuchi K, Yoshikawa J: Implications of plasma concentrations of adiponectin in patients with coronary artery disease. Heart 2004, 90:528-533.

21. Lee BJ, Huang YC, Chen SJ, Lin PT: Effects of coenzyme Q10 supplementation on inflammatory markers (high sensitivity C-reactive protein, interleukin- 6 and homocysteine) in patients with coronary artery. Nutrition 2012, 28:767-772.

22. Karpińska J, Mikołuć B, Motkowski R, Piotrowska-Jastrzebska J: HPLC method for simultaneous determination of retinol, alpha-tocopherol and coenzyme Q10 in human plasma. J Pharm Biomed Anal 2006, 42:232-236.

23. Littarru GP, Mosca F, Fattorini D, Bompadre S: Method to assay coenzyme Q10 in blood plasma or blood serum. U S Pat 2007, 7303921.

24. Paglia D, Valentine W: Studies on the qualitative characterization of erythrocyte glutathione peroxidase. J Lab Clin Med 1967, 70:159-169.

25. Marklund S, Marklund G: Involvement of superoxide anion radical in autoxidation of pyrogallol and a convenient assay for superoxide dismutase. Eur J Biochem 1974, 47:469-474.

26. Aebi H: Catalase in vitro. Methods. Enzymol 1984, 105:121-126.

27. Tiano L, Belardinelli R, Carnevali P, Principi F, Seddaiu G, Littarru GP: Effect of coenzyme Q10 administration on endothelial function and extracellular superoxide dismutase in patients with ischaemic heart disease: a double-blind, randomized controlled study. Eur Heart J 2007, 28:2249-2255

28. Bahorun T, Soobrattee MA, Luximon-Ramma V, Aruoma OI: Free radicals and antioxidants in cardiovascular health and disease. Internet J Med Update 2006, 1:25-41.

29. Molyneux SL, Young JM, Florkowski CM, Lever M, Georgr PM: Coenzyme Q10: is there a clinical role and a case for measurement? Clin Biochem Rev 2008, 29:71-82.

30. Stocker R, Bowry W, Frei B: Ubiquinol-10 protects human low density lipoprotein more efficiently against lipid peroxidation than does alpha-tocopherol. Proc Natl Acad Sci U S A 1991, 88:1646-1650.

31. Constantinescu A, Maguire JJ, Packer L: Interactions between ubiquinones and vitamins in membranes and cells. Mol Aspects Med 1994, 15:s57-s65.

32. Stoyanovsky DA, Osipov AN, Quinn PJ, Kagan VE: Ubiquinone-dependent recycling of vitamin E radicals by superoxide. Arch Biochem Biophys 1995, 323:343-351.

33. Lass A, Sohal RS: Electron transport-linked ubiquinone-dependent recycling of a-tocopherol inhibits autooxidation of mitochondrial membranes. Arch Biochem Biophys 1998, 352:229-236.

34. Schmelzer C, Lindner I, Rimbach G, Niklowitz P, Menke T, Doring F: Functions of coenzyme Q10 in inflammation and gene expression. Biofactors 2008, 32:179-183.

35. Schmelzer C, Lorenz G, Rinbach G, Doring F: In vitro effects of the reduced form of coenzyme $Q(10)$ on secretion levels of TNF-alpha and Chemokines in response to LPS in the human monocytic cell line THP-1. J Clin Biochem Nutr 2009, 44:62-66. 
36. Zhang YP, Eber A, Yuan $Y$, Yang Z, Rodriguez $Y$, Levitt RC, Takacs $P$, Candiotti KA: Prophylactic and antinociceptive effects of coenzyme Q10 on diabetic neuropathic pain in a mouse model of type 1 diabetes. Anesthesiology 2013, 118:945-954.

37. Pischon T, Girman GJ, Hotamisligil GS, Rifai N, Hu FB, Rimm EB: Plasma adiponectin levels and risk of myocardial infarction in Men. JAMA 2004, 291:1730-1737.

doi:10.1186/1475-2891-12-142

Cite this article as: Lee et al:: Effects of coenzyme Q10 supplementation

( $300 \mathrm{mg} /$ day) on antioxidation and anti-inflammation in coronary artery

disease patients during statins therapy: a randomized, placebo-controlled

trial. Nutrition Journal 2013 12:142

\section{Submit your next manuscript to BioMed Central and take full advantage of:}

- Convenient online submission

- Thorough peer review

- No space constraints or color figure charges

- Immediate publication on acceptance

- Inclusion in PubMed, CAS, Scopus and Google Scholar

- Research which is freely available for redistribution 